\title{
PENGARUH FAKTOR KONSEP KENDIRI, KESEDARAN KOMUNITI DAN SOKONGAN SOSIAL TERHADAP PENGINTEGRASIAN SOSIAL BAGI PESALAH MUDA DI MALAYSIA
}

\section{THE INFLUENCE OF SELF-CONCEPT, SENSE OF COMMUNITY AND SOCIAL SUPPORT TOWARDS SOCIAL INTEGRATION AMONG YOUNG OFFENDERS IN MALAYSIA}

\section{N.K. Tharshini ${ }^{1 *}$, Fauziah Ibrahim ${ }^{2}$, Mohd Suhaimi Mohamad ${ }^{2}$ dan Ezarina Zakaria $^{2}$}

${ }^{1}$ Fakulti Sains Sosial dan Kemanusiaan, Universiti Malaysia Sarawak, Sarawak, MALAYSIA

${ }^{2}$ Fakulti Sains Sosial dan Kemanusiaan, Universiti Kebangsaan Malaysia, Selangor, MALAYSIA

*Corresponding author: stharshini@unimas.my

Published online: 30 April 2021

To cite this article: N.K. Tharshini, Fauziah Ibrahim, Mohd Suhaimi Mohamad and Ezarina Zakaria. 2021. Pengaruh faktor konsep kendiri, kesedaran komuniti dan sokongan sosial terhadap pengintegrasian sosial bagi pesalah muda di Malaysia. Kajian Malaysia 39(1): 117-140. https://doi.org/10.21315/km2021.39.1.6

To link to this article: https://doi.org/10.21315/km2021.39.1.6

\section{ABSTRACT}

Social integration is an important aspect to prevent young offenders from being involved in criminal activities and motivates them to lead a positive lifestyle. Therefore, this article discusses the influence of self-concept, sense of community and social support towards social integration among young offenders in Malaysia. Data were collected using a quantitative approach based on cross-sectional survey design among 306 young offenders undergoing Community Service Order initiated by the Department of Social Welfare. The resultant data were analysed using IBM for SPSS version 23.0. A majority of respondents who took part in this study consisted of male young offenders aged 20 years old, single in marital status, completed educational level up to Sijil Pelajaran Malaysia (SPM), were unemployed and were involved in theft. The findings via multiple regression analysis indicate that social support $(\beta=0.440, p<0.01)$ is the main factor that contributes to social integration among young offenders. As an overall impact, 
the study's implications to concerned parties include calls to improve the existing module and rehabilitation programme in order to help young offenders succeed in the process of social integration.

Keywords: self-concept, sense of community, social support, social integration, young offender

\begin{abstract}
ABSTRAK
Pengintegrasian sosial merupakan satu aspek penting yang perlu diberi perhatian memandangkan dimensi ini mampu membantu pesalah muda agar tidak terlibat semula dengan salah laku jenayah serta mendorong mereka untuk menjalani kehidupan baharu yang sejahtera. Oleh yang demikian, artikel ini disediakan untuk mengenal pasti pengaruh faktor konsep kendiri, kesedaran komuniti dan sokongan sosial terhadap pengintegrasian sosial bagi pesalah muda di Malaysia. Satu kajian kuantitatif dengan menggunakan reka bentuk tinjauan keratan rentas telah dijalankan ke atas 306 orang pesalah muda yang sedang menjalani hukuman Perintah Khidmat Masyarakat di bawah pengawasan Jabatan Kebajikan Masyarakat. Data kajian dianalisis menggunakan IBM for SPSS versi 23.0. Hasil kajian menunjukkan bahawa majoriti daripada responden yang terlibat dalam kajian ini terdiri daripada pesalah muda lelaki yang berusia 20 tahun, bujang, berpendidikan pada tahap Sijil Pelajaran Malaysia (SPM), tidak bekerja serta terlibat dengan kesalahan mencuri. Keputusan analisis regresi berganda mendapati bahawa faktor sokongan sosial $(\beta=0.440, p<0.01)$ merupakan penyumbang signifikan terhadap pengintegrasian sosial. Dapatan kajian memberi implikasi kepada pihak yang berkepentingan dalam menambah baik modul dan program pemulihan yang sedia ada agar pesalah muda berjaya dalam proses pengintegrasian sosial.
\end{abstract}

Kata kunci: konsep kendiri, kesedaran komuniti, sokongan sosial, pengintegrasian sosial, pesalah muda

\title{
PENDAHULUAN
}

Ahli sosiologi Perancis, Durkheim (1897) telah memperkenalkan istilah pengintegrasian sosial pada akhir abad ke-19. Bermula pada awal abad ke-20, konsep pengintegrasian sosial mula digunakan secara meluas dalam bidang sosiologi, antropologi, ekonomi, biologi (sains kesihatan) dan psikologi kerana ia mampu menjelaskan secara mendalam mengenai konsep kesamarataan, 
perpaduan dan perapatan yang wujud di antara manusia. Menurut United Nations (2012), pengintegrasian sosial mewujudkan perasaan dihargai serta menyebabkan seseorang individu mula menghormati dan mempercayai satu sama lain tanpa mengambil kira perbezaan yang wujud dari aspek gender, agama dan pemahaman ideologi.

Secara amnya, konsep pengintegrasian sosial merujuk kepada suatu keadaan di mana sekumpulan individu yang telah diberi pelabelan sebagai "golongan minoriti" atau "golongan terpinggir" bergabung secara sukarela bagi membina identiti diri yang positif dalam komuniti (Durkheim 1897). Menurut Durkheim (1897) juga, pengintegrasian sosial yang berjaya melibatkan perkongsian sumber sedia ada dalam komuniti yang menyebabkan seseorang individu merasakan bahawa dirinya adalah sebahagian daripada sistem sosial. Dalam bidang jenayah pula, istilah pengintegrasian sosial digunakan bagi mengaitkan interaksi yang wujud antara banduan dengan persekitaran sosial (ahli keluarga, rakan sebaya, jiran tetangga dan anggota masyarakat). Menurut pandangan Smallbone, Marshall dan Wortley (2013), apabila seseorang banduan merasakan bahawa dirinya dihargai dan diterima oleh individu lain, maka ikatan kasih sayang yang kuat terjalin di antara mereka. Keadaan ini bukan sahaja memudahkan proses pengintegrasian sosial bahkan turut membantu banduan tersebut menjadi sebahagian daripada anggota masyarakat tanpa dibelenggu dengan masalah stigma dan stereotaip (Pierson 2010; Smallbone, Marshall dan Wortley 2013).

United Nations Basic Principles for the Treatment of Prisoners menggariskan empat elemen penting untuk berjaya dalam proses pengintegrasian sosial, iaitu: (1) komuniti memainkan peranan utama dalam memudahkan proses pengintegrasian sosial; (2) status pekerjaan yang tetap membantu mempercepatkan proses pengintegrasian sosial; (3) individu memerlukan pendidikan dan kemahiran untuk berjaya dalam proses pengintegrasian sosial; dan (4) agensi perkhidmatan awam perlu memberikan latihan dan kemahiran vokasional kepada banduan untuk membantu mereka berjaya dalam proses pengintegrasian sosial (United Nations 2012; Mohd Al Adib dan Noor Aziah 2014). Selain itu, menurut pandangan Teplin et al. (2006), Lebel (2012) dan Motzkin et al. (2012), seseorang banduan akan berjaya dalam proses pengintegrasian sosial sekiranya mereka mempunyai konsep kendiri yang positif, kesedaran komuniti yang tinggi serta menerima sokongan sosial yang berterusan daripada individu yang signifikan dalam kehidupan mereka.

Kajian yang telah dijalankan oleh Marsh (1990), Turner dan Jannetta (2010), Pilarska dan Suchanska (2015) serta Suszeka et al. (2018) mendapati bahawa banduan yang mempunyai konsep kendiri yang positif mempamerkan personaliti 
diri yang unggul serta lebih bersedia menghadapi cabaran dalam proses mengintegrasikan diri dalam persekitaran sosial selepas dibebaskan daripada penjara. Menurut Beaver et al. (2009) serta Pilarska dan Suchanska (2015), pesalah dewasa yang mempunyai konsep kendiri yang positif akan cepat mengadaptasikan diri dalam persekitaran sosial manakala Rohany et al. (2011) mendapati bahawa konsep kendiri yang positif dapat dibina dalam diri pesalah juvana sekiranya mereka menerima sokongan moral yang berterusan daripada ahli keluarga. Hal ini dikatakan demikian kerana sokongan dan dorongan yang diberikan oleh ahli keluarga mampu mewujudkan persekitaran keluarga yang kondusif, merangsang perkembangan fizikal dan emosional serta menyebabkan pesalah juvana berasa selamat dan disayangi oleh individu yang signifikan dalam kehidupan mereka (Rohany et al. 2011).

Menurut pandangan Salzer dan Baron (2006) serta Turner dan Jannetta (2010), banduan yang mempunyai konsep kendiri negatif akan berhadapan dengan kesukaran untuk mengintegrasikan diri bersama ahli keluarga kerana mempunyai rasa bersalah yang tinggi disebabkan pernah terlibat dengan salah laku jenayah. Maruna (2001) mendapati bahawa kebanyakan daripada banduan yang mempunyai konsep kendiri yang negatif akan mengelakkan diri daripada berhubung dengan rakan sebaya selepas keluar daripada penjara kerana dibelenggu dengan perasaan rendah diri. Selain itu, dapatan kajian oleh Zainah et al. (2011) menunjukkan bahawa pesalah muda yang mempunyai konsep kendiri negatif tidak menunjukkan hubungan yang rapat bersama ahli keluarga mereka. Zainah et al. (2011) turut menjelaskan bahawa kebanyakan pesalah muda yang mempunyai konsep kendiri yang negatif membesar dalam persekitaran keluarga yang tidak stabil (kefungsian keluarga negatif iaitu kurang berkongsi perasaan, jarang meluangkan masa lapang bersama ahli keluarga dan corak komunikasi yang tidak efektif).

Selain faktor konsep kendiri, dimensi kesedaran komuniti juga merupakan penyumbang signifikan kepada pengintegrasian sosial yang berjaya. Secara lazimnya, kesedaran komuniti yang tinggi memberi keyakinan kepada banduan untuk masuk semula ke dalam komuniti dengan identiti diri yang positif serta mengelakkan mereka daripada mengasingkan diri dalam persekitaran sosial (Camp, Finlay dan Lyons 2002). Greeno dan Kim (2008), Beaver et al. (2009) serta Serin, Mailloux dan Wilson (2011) menjelaskan bahawa tahap kesedaran komuniti bagi banduan wanita adalah lebih rendah berbanding banduan lelaki kerana golongan wanita lebih bersifat emosional, mudah berasa ragu terhadap kebolehan diri sendiri serta lebih takut untuk berhadapan dengan anggota masyarakat kerana mempunyai status sebagai "bekas pesalah" berbanding banduan lelaki. 
Hasil kajian Cullen (2011) menunjukkan bahawa pesalah lelaki yang mempunyai tahap kesedaran komuniti yang tinggi berasa yakin serta lebih bersedia untuk kembali semula ke pangkuan komuniti selepas menamatkan tempoh hukuman. Selain itu, Laub dan Sampson (2001), Mashek, Cannaday dan Tangney (2007), Carr dan Steele (2009) serta Felson dan Kreager (2015) menjelaskan bahawa pesalah muda bermotivasi tinggi serta lebih bersedia untuk menjadi sebahagian daripada anggota masyarakat sekiranya mereka menerima sokongan moral yang berterusan daripada ahli keluarga dan rakan sebaya.

Selari dengan dimensi konsep kendiri dan kesedaran komuniti, faktor sokongan sosial juga merupakan elemen penting untuk berjaya dalam proses pengintegrasian sosial (United Nations 2012). Secara amnya, proses penahanan dalam penjara akan mewujudkan perasaan trauma dalam diri banduan kerana mereka perlu berpisah dengan ahli keluarga untuk suatu tempoh masa tertentu (Grimm et al. 2009). Oleh yang demikian, sokongan dan penerimaan positif daripada ahli keluarga dan anggota masyarakat adalah amat penting agar banduan dapat mengintegrasikan diri dalam komuniti tanpa perlu berhadapan dengan masalah stigma (Grimm et al. 2009). Menurut Teplin et al. (2006), pesalah muda yang kurang menerima sokongan sosial daripada ahli keluarga lebih berisiko tinggi untuk terlibat semula dengan aktiviti jenayah serta sukar mengintegrasikan diri bersama adik-beradik, saudara-mara dan rakan sebaya selepas dibebaskan daripada institusi pemulihan akhlak.

Dapatan kajian Syme (2000) serta Demaray dan Malecki (2014) menjelaskan bahawa sokongan sosial yang tinggi memberi keyakinan kepada banduan untuk masuk semula ke dalam komuniti dengan identiti diri yang positif serta berisiko rendah untuk terjebak semula dengan jenayah kekerasan dan jenayah harta benda. Selain itu, Wasserman et al. (2003) menjelaskan bahawa banduan wanita lebih mengharapkan sokongan emosi daripada ahli keluarga, sebaliknya banduan lelaki pula memerlukan sokongan moral daripada rakan sebaya untuk mengintegrasikan diri dalam komuniti.

Memandangkan dimensi konsep kendiri, kesedaran komuniti dan sokongan sosial merupakan elemen penting bagi membantu seseorang individu untuk berjaya dalam proses pengintegrasian sosial, maka kajian ini dijalankan untuk mengenal pasti pengaruh faktor konsep kendiri, kesedaran komuniti dan sokongan sosial terhadap pengintegrasian sosial bagi pesalah muda di Malaysia. 


\section{OBJEKTIF KAJIAN}

Objektif kajian ini adalah untuk:

1. Mengkaji profil demografi bagi pesalah muda di Malaysia.

2. Mengenal pasti pengaruh faktor konsep kendiri, kesedaran komuniti dan sokongan sosial terhadap pengintegrasian sosial bagi pesalah muda di Malaysia.

\section{REKA BENTUK KAJIAN}

Reka bentuk kajian merupakan perancangan untuk menjalankan sesebuah penyelidikan secara efektif berpandukan kepada masalah yang ingin dikaji oleh pengkaji (Frankfort dan Nachmias 2000). Menurut Creswell dan Plano (2011), reka bentuk kajian bertujuan untuk membantu pengkaji menentukan prosedur dan kaedah untuk mengumpul, menganalisis, menginterpretasi dan melaporkan data yang diperoleh dalam sesuatu kajian.

Dalam kajian ini, reka bentuk kajian secara tinjauan keratan rentas serta pendekatan kuantitatif digunakan untuk mengumpul data kajian. Kaedah tinjauan keratan rentas membenarkan pengkaji mengumpul data pada suatu masa yang ditetapkan berdasarkan kepada atribut responden yang sedia ada manakala pendekatan kuantitatif memberi penekanan kepada fenomena objektif yang dikawal melalui pengumpulan dan penganalisaan data (Chua 2009).

\section{LOKASI KAJIAN}

Pemilihan lokasi kajian dilakukan berasaskan kepada bilangan pesalah muda yang sedang menjalani hukuman Perintah Khidmat Masyarakat di empat zon yang berbeza iaitu utara, tengah, selatan dan timur. Bagi setiap zon, dua buah institusi Jabatan Kebajikan Masyarakat (JKM) yang mempunyai bilangan pesalah muda yang tertinggi dipilih sebagai lokasi kajian. Pembahagian zon memudahkan proses pengumpulan data serta bertujuan untuk memastikan bahawa jumlah sampel yang seimbang dipilih bagi mewakili setiap zon yang berbeza. Seterusnya, pemilihan pesalah muda bagi setiap zon dilakukan secara rawak agar sampel dapat mewakili setiap zon berkenaan, mewakili ciri-ciri populasi kajian dengan lebih luas dan memenuhi keperluan kajian (De Vaus 1993). Jadual 1 menunjukkan pemilihan lokasi kajian mengikut zon. 
Jadual 1: Pemilihan lokasi kajian mengikut zon

\begin{tabular}{ll}
\hline Zon & Institusi \\
\hline Utara & JKM Kedah \\
& JKM Pulau Pinang \\
Tengah & JKM Selangor \\
& JKM Wilayah Persekutuan Kuala Lumpur \\
Timur & JKM Pahang \\
& JKM Kelantan \\
Selatan & JKM Melaka \\
& JKM Johor \\
\hline
\end{tabular}

\section{POPULASI KAJIAN}

Menurut Frankfort dan Nachmias (2000), populasi ialah sekumpulan individu, kumpulan atau organisasi yang hendak dikaji oleh pengkaji. Populasi juga merupakan satu elemen yang telah diperincikan secara teori yang merangkumi semua individu yang mengambil bahagian dalam sesuatu kajian (Wallace dan Van Fleet 2012). Dalam kajian ini, populasi merujuk kepada pesalah muda yang terdiri daripada tiga kumpulan etnik utama di Malaysia iaitu Melayu, Cina dan India yang sedang menjalani hukuman Perintah Khidmat Masyarakat di bawah pantauan JKM.

\section{PERSAMPELAN KAJIAN}

Suatu populasi adalah terlalu besar atau terlalu ramai untuk dikaji. Oleh itu, sebahagian daripada populasi yang dipilih untuk tujuan kajian dikenali sebagai sampel kajian (Finks dan Kosekoff 1985). Menurut Chua (2009), sampel kajian merupakan subset kepada populasi. Selain itu, proses pemilihan sampel kajian adalah amat penting memandangkan sampel akan memberi gambaran keseluruhan mengenai isu yang ingin dikaji oleh pengkaji (Wallace dan Van Fleet 2012).

Dalam kajian ini, saiz sampel ditentukan berpandukan kepada jadual penentuan saiz sampel yang diperkenalkan oleh Cohen, Manion dan Morrison (2001). Penentuan saiz sampel seharusnya mengambil kira aras kesignifikanan pada $p<0.05$ (aras keertian $=95 \%)($ Cohen, Manion dan Morrison 2001). Menurut Cohen, Manion dan Morrison (2001) lagi, sekiranya populasi bagi sesuatu kajian adalah 540 orang dan aras kesignifikanan yang diperlukan ialah 0.05, maka bilangan sampel yang disarankan adalah sebanyak 278 orang. Bagi menampung 
kesilapan pengisian borang soal selidik oleh responden atau keciciran yang mungkin berlaku atas kecuaian pengkaji, maka sebanyak 28 orang responden (10\%) ditambah kepada saiz sampel asal. Perkara ini selari dengan pandangan Tuckman (1988) yang menjelaskan bahawa saiz sampel perlu dimaksimumkan agar ralat persampelan dapat diminimumkan. Oleh yang demikian, saiz sampel yang digunakan dalam kajian ini adalah sebanyak 306 orang.

\section{Kriteria Pemilihan Sampel Kajian}

Pemilihan sampel dalam kajian ini adalah berasaskan kepada tiga kriteria iaitu:

1. Purata umur responden kajian adalah di antara 18 hingga 21 tahun.

2. Responden merupakan pesalah lelaki yang sedang menjalani hukuman Perintah Khidmat Masyarakat.

3. Responden telah menyempurnakan perintah sekurang-kurangnya selama dua bulan (minimum).

\section{INSTRUMEN KAJIAN}

Instrumen kajian adalah penting untuk mencapai objektif penyelidikan yang telah ditetapkan (De Vaus 1993). Kesemua instrumen yang digunakan dalam kajian ini adalah instrumen terbuka yang boleh digunakan oleh orang awam untuk tujuan menjalankan penyelidikan. Skala Likert digunakan kerana mempunyai kebolehpercayaan yang tinggi berbanding skala lain (Lancaster, Dodd dan Williamson 2004; Chua 2014). Dalam kajian ini, pengkaji menggunakan borang soal selidik yang terdiri daripada empat bahagian utama untuk mengumpul data kajian.

\section{Konsep Kendiri}

Konsep kendiri pesalah muda diukur dengan menggunakan Multidimensional Self-Concept Scale yang mengandungi 36 item yang dibina oleh Fleming dan Courtney (1984). Konsep kendiri dibahagikan kepada lima dimensi utama iaitu harga diri, keyakinan sosial, pencapaian akademik, penampilan diri dan kebolehan fizikal. Setiap item ini diukur menggunakan skala Likert lima mata iaitu (1) sangat tidak kerap; (2) tidak kerap; (3) tidak pasti; (4) kerap; dan (5) sangat kerap. Jadual 2 menunjukkan beberapa contoh item soalan bagi dimensi konsep kendiri. 
Jadual 2: Contoh item soalan bagi dimensi konsep kendiri

\begin{tabular}{lccccc}
\hline Pernyataan & $\begin{array}{c}\text { Sangat tidak } \\
\text { kerap }\end{array}$ & $\begin{array}{c}\text { Tidak } \\
\text { kerap }\end{array}$ & $\begin{array}{c}\text { Tidak } \\
\text { pasti }\end{array}$ & Kerap & $\begin{array}{c}\text { Sangat } \\
\text { kerap }\end{array}$ \\
\hline $\begin{array}{l}\text { Sejauh mana anda yakin dengan kebolehan } \\
\text { diri sendiri? }\end{array}$ & 1 & 2 & 3 & 4 & 5 \\
$\begin{array}{l}\text { Sekerap mana anda berasa bimbang tentang } \\
\text { tanggapan orang lain terhadap diri anda? }\end{array}$ & 1 & 2 & 3 & 4 & 5 \\
$\begin{array}{l}\text { Pernahkah anda terfikir bahawa anda } \\
\text { seorang yang tidak berguna? }\end{array}$ & 1 & 2 & 3 & 4 & 5 \\
\hline
\end{tabular}

\section{Kesedaran Komuniti}

Kesedaran komuniti pesalah muda diukur dengan menggunakan skala Sense of Community Index 2 (SCI-2) yang mengandungi 24 item yang dibina oleh Chavis, Lee dan Acosta (2008). Kesedaran komuniti dibahagikan kepada empat dimensi utama iaitu pengukuhan keperluan, keahlian, pengaruh komuniti dan keterikatan emosi. Setiap item diukur menggunakan skala Likert lima mata iaitu (1) sangat tidak setuju; (2) tidak setuju; (3) tidak pasti; (4) setuju; dan (5) sangat setuju. Jadual 3 menunjukkan beberapa contoh item soalan bagi dimensi kesedaran komuniti.

Jadual 3: Contoh item soalan bagi dimensi kesedaran komuniti

\begin{tabular}{lccccc}
\hline Pernyataan & $\begin{array}{c}\text { Sangat tidak } \\
\text { setuju }\end{array}$ & $\begin{array}{c}\text { Tidak } \\
\text { setuju }\end{array}$ & $\begin{array}{c}\text { Tidak } \\
\text { pasti }\end{array}$ & Setuju & $\begin{array}{c}\text { Sangat } \\
\text { setuju }\end{array}$ \\
\hline $\begin{array}{l}\text { Keperluan utama saya dipenuhi kerana } \\
\text { saya sebahagian daripada ahli komuniti } \\
\text { ini. }\end{array}$ & 1 & 2 & 3 & 4 & 5 \\
$\begin{array}{l}\text { Setiap ahli komuniti mempunyai } \\
\text { keperluan, keutamaan dan matlamat } \\
\text { yang sama. }\end{array}$ & 1 & 2 & 3 & 4 & 5 \\
$\begin{array}{l}\text { Saya berasa bangga kerana menjadi } \\
\text { sebahagian daripada ahli komuniti ini. }\end{array}$ & 1 & 2 & 3 & 4 & 5 \\
\hline
\end{tabular}

\section{Sokongan Sosial}

Sokongan sosial pesalah muda diukur dengan menggunakan skala Interpersonal Support Evaluation List (ISEL) yang mengandungi 40 item yang dibina oleh Cohen dan Hoberman (1983). Sokongan sosial dibahagikan kepada empat elemen utama iaitu sokongan penilaian, sokongan nyata, sokongan kendiri dan sokongan kebersamaan. Setiap item ini diukur menggunakan skala Likert lima mata iaitu 
(1) sangat tidak setuju; (2) tidak setuju; (3) tidak pasti; (4) setuju; dan (5) sangat setuju. Jadual 4 menunjukkan beberapa contoh item soalan bagi dimensi sokongan sosial.

Jadual 4: Contoh item soalan bagi dimensi sokongan sosial

\begin{tabular}{lccccc}
\hline Pernyataan & $\begin{array}{c}\text { Sangat tidak } \\
\text { setuju }\end{array}$ & $\begin{array}{c}\text { Tidak } \\
\text { setuju }\end{array}$ & $\begin{array}{c}\text { Tidak } \\
\text { pasti }\end{array}$ & Setuju & $\begin{array}{c}\text { Sangat } \\
\text { setuju }\end{array}$ \\
\hline $\begin{array}{l}\text { Saya mempunyai beberapa orang yang } \\
\text { boleh dipercayai untuk membantu } \\
\text { menyelesaikan masalah saya. }\end{array}$ & 1 & 2 & 3 & 4 & 5 \\
$\begin{array}{l}\text { Apabila berasa sunyi, saya mempunyai } \\
\text { beberapa orang untuk berbual dengan saya. }\end{array}$ & 1 & 2 & 3 & 4 & 5 \\
$\begin{array}{l}\text { Kebanyakan orang yang saya kenali } \\
\text { memandang tinggi terhadap saya. }\end{array}$ & 1 & 2 & 3 & 4 & 5 \\
\hline
\end{tabular}

\section{Pengintegrasian Sosial}

Pengintegrasian sosial pesalah muda diukur dengan menggunakan The Social Integration Scale yang mengandungi 26 item yang dibina oleh Susan dan Murray (1995). Pengintegrasian sosial dibahagikan kepada lima dimensi utama iaitu kepercayaan, rakan terlibat jenayah, ketersediaan rangkaian sosial, komitmen, dan penglibatan sosial. Setiap item ini diukur menggunakan skala Likert lima mata iaitu (1) sangat tidak setuju; (2) tidak setuju; (3) tidak pasti; (4) setuju; dan (5) sangat setuju. Jadual 5 menunjukkan beberapa contoh item soalan bagi dimensi pengintegrasian sosial.

Jadual 5: Contoh item soalan bagi dimensi pengintegrasian sosial

\begin{tabular}{lccccc}
\hline Pernyataan & $\begin{array}{c}\text { Sangat tidak } \\
\text { setuju }\end{array}$ & $\begin{array}{c}\text { Tidak } \\
\text { setuju }\end{array}$ & $\begin{array}{c}\text { Tidak } \\
\text { pasti }\end{array}$ & Setuju & $\begin{array}{c}\text { Sangat } \\
\text { setuju }\end{array}$ \\
\hline $\begin{array}{l}\text { Saya mempunyai rakan-rakan yang pernah } \\
\text { melakukan kesalahan jenayah. }\end{array}$ & 1 & 2 & 3 & 4 & 5 \\
$\begin{array}{l}\text { Saya banyak meluangkan masa untuk } \\
\text { melakukan kerja-kerja sukarela. }\end{array}$ & 1 & 2 & 3 & 4 & 5 \\
$\begin{array}{l}\text { Tidak salah sekiranya berbohong untuk } \\
\text { mengelakkan diri daripada terlibat dengan } \\
\text { sesuatu masalah. }\end{array}$ & 1 & 2 & 3 & 4 & 5 \\
\hline
\end{tabular}




\section{KESAHAN INSTRUMEN KAJIAN}

Frankfort dan Nachmias (2000) menjelaskan bahawa kesahan instrumen kajian perlu dilakukan bagi mengenal pasti sama ada alat kajian benar-benar menguji sesuatu perkara yang hendak dikaji. Dalam kajian ini, pengkaji menggunakan kesahan kandungan untuk memurni dan menyelaras soalan-soalan yang terdapat dalam borang soal selidik (Standards for Educational and Psychological Testing 1985). Selain itu, pengkaji telah memastikan bahawa pemboleh ubah dalam kajian ini didefinisikan dengan jelas, tepat dan mudah difahami bagi menjamin nilai kesahan yang tinggi.

\section{Kesahan Kandungan}

Kesahan kandungan bertujuan untuk mengenal pasti sejauh mana sesuatu konsep berjaya didefinisikan sepenuhnya (Sekaran dan Bougie 2011). Selain itu, kesahan kandungan juga berfungsi untuk menyelaraskan item-item yang terdapat dalam instrumen kajian supaya bertepatan dan membawa maksud yang sama dengan instrumen kajian yang asal selepas penterjemahan secara back-to-back translation dijalankan sepertimana yang dicadangkan oleh Brislin, Lonner dan Thorndike (1973). Dalam kajian ini, sejumlah 126 item soalan telah dimurnikan dengan bantuan panel pakar. Menurut Othman (1999), enam hingga sembilan orang panel adalah mencukupi untuk membuat penilaian terhadap konstruk dan item kajian. Oleh yang demikian, seramai empat orang pensyarah dari Pusat Penyelidikan Psikologi dan Kesejahteraan Manusia, Universiti Kebangsaan Malaysia serta dua orang pegawai JKM (JKM Kajang) yang bertugas mengendalikan pesalah muda yang terlibat dengan hukuman Perintah Khidmat Masyarakat telah memberi kerjasama untuk menilai borang soal selidik yang digunakan dalam kajian ini.

Secara amnya, panel dipilih berdasarkan kepada kepakaran mereka dalam bidang kerja sosial, psikologi, jenayah dan pembangunan komuniti serta mempunyai pengalaman sebagai ahli akademik dan pengalaman bekerja lebih dari lima tahun bagi pegawai JKM. Secara lazimnya, penilaian dilakukan berdasarkan kepada empat skor utama iaitu (1) tidak relevan; (2) agak relevan; (3) cukup relevan; dan (4) sangat relevan. Setelah meneliti pandangan panel, sebanyak 31 item soalan telah dimurnikan dari segi penggunaan struktur ayat dan kesesuaiannya dengan konstruk kajian. 


\section{KEBOLEHPERCAYAAN INSTRUMEN KAJIAN}

Kebolehpercayaan merujuk kepada ketepatan, ketekalan dan kestabilan alat ukuran yang digunakan dalam sesuatu kajian (Baker 1994). Menurut Frankfort dan Nachmias (2000), kebolehpercayaan instrumen kajian merujuk kepada keupayaan untuk memperoleh nilai yang sama apabila pengukuran yang sama diulang. Nilai pekali kebolehpercayaan yang dianggap baik adalah antara 0.80 hingga 0.90 manakala nilai kebolehpercayaan 0.70 hingga 0.80 ialah nilai yang memuaskan untuk tujuan kajian (Chua 2014). Dalam kajian ini, alfa Cronbach ( $\alpha$ ) melebihi 0.70 digunakan sebagai petunjuk kepada pengukuran kajian. Jadual 6 menunjukkan ringkasan nilai kebolehpercayaan alat ukuran yang digunakan dalam kajian ini.

Jadual 6: Keputusan nilai kebolehpercayaan instrumen kajian

\begin{tabular}{lc}
\hline Pemboleh ubah & Nilai $\alpha(n=306)$ \\
\hline Konsep kendiri & 0.90 \\
Kesedaran komuniti & 0.88 \\
Sokongan sosial & 0.86 \\
Pengintegrasian sosial & 0.86 \\
\hline
\end{tabular}

\section{DAPATAN KAJIAN DAN PERBINCANGAN}

\section{Profil Demografi bagi Pesalah Muda di Malaysia}

Profil demografi dalam kajian ini mewakili maklumat asas yang berkaitan dengan pesalah muda yang sedang menjalani hukuman Perintah Khidmat Masyarakat. Hasil analisis deskriptif menunjukkan bahawa majoriti daripada responden yang terlibat dalam kajian ini merupakan pesalah lelaki (100\%) yang berusia 20 tahun (36.3\%) serta berbangsa Melayu (90.5\%). Selain itu, kebanyakan daripada responden masih berstatus bujang $(94.4 \%)$, telah menamatkan persekolahan pada tahap tingkatan 5 (Sijil Pelajaran Malaysia, SPM) (52.1\%), tidak bekerja (49.7\%) serta terlibat dengan kesalahan mencuri (26.1\%). Jadual 7 menunjukkan profil demografi bagi pesalah muda di Malaysia. 
Jadual 7: Profil demografi pesalah muda

\begin{tabular}{|c|c|c|}
\hline Profil demografi & $n=306$ & $\%$ \\
\hline \multicolumn{3}{|l|}{ Umur } \\
\hline 18 tahun & 50 & 16.3 \\
\hline 19 tahun & 83 & 27.1 \\
\hline 20 tahun & 111 & 36.3 \\
\hline 21 tahun & 62 & 20.3 \\
\hline \multicolumn{3}{|l|}{ Jantina } \\
\hline Lelaki & 306 & 100 \\
\hline \multicolumn{3}{|l|}{ Etnik } \\
\hline Melayu & 277 & 90.5 \\
\hline Cina & 14 & 4.6 \\
\hline India & 15 & 4.9 \\
\hline \multicolumn{3}{|l|}{ Status perkahwinan } \\
\hline Bujang & 289 & 94.4 \\
\hline Berkahwin & 17 & 5.6 \\
\hline \multicolumn{3}{|l|}{ Taraf pendidikan } \\
\hline Tidak bersekolah & 13 & 4.2 \\
\hline Sekolah rendah & 22 & 7.2 \\
\hline PMR & 83 & 27.1 \\
\hline SPM & 159 & 52.1 \\
\hline STPM & 5 & 1.6 \\
\hline Sijil kemahiran & 20 & 6.5 \\
\hline Diploma & 4 & 1.3 \\
\hline \multicolumn{3}{|l|}{ Status pekerjaan } \\
\hline Pelajar & 43 & 14.1 \\
\hline Tidak bekerja & 152 & 49.7 \\
\hline Bekerja & 51 & 16.7 \\
\hline Kerja sambilan & 60 & 19.5 \\
\hline \multicolumn{3}{|l|}{ Jenis-jenis kesalahan } \\
\hline Mencuri & 80 & 26.1 \\
\hline Lalu lintas & 71 & 23.2 \\
\hline Pecah rumah & 55 & 18.0 \\
\hline Dadah & 35 & 11.7 \\
\hline Ragut & 31 & 10.1 \\
\hline Bergaduh & 16 & 5.2 \\
\hline Senjata api & 8 & 2.6 \\
\hline Daun ketum & 3 & 1.0 \\
\hline Gaduh & 2 & 0.6 \\
\hline Menyimpan harta curi & 2 & 0.6 \\
\hline Langgar perintah PLKN & 1 & 0.3 \\
\hline Pecah amanah & 1 & 0.3 \\
\hline Cubaan merogol & 1 & 0.3 \\
\hline
\end{tabular}

Nota PMR $=$ Penilaian Menengah Rendah; STPM = Sijil Tinggi Persekolahan Malaysia; PLKN $=$ Program Latihan Khidmat Negara. 
Berdasarkan aspek profil demografi pesalah muda, hasil kajian mendapati bahawa sebilangan besar daripada responden yang terlibat dalam kajian ini berusia 20 tahun. Faktor berisiko seperti naluri memberontak yang tinggi, kawalan diri yang rendah serta ketidakstabilan emosi yang sememangnya wujud pada peringkat usia tersebut ternyata telah mendorong pesalah muda untuk terlibat dengan gejala antisosial (Piquero et al. 2015). Penelitian terperinci berkaitan trend jenayah di Malaysia memberi gambaran jelas bahawa golongan lelaki lebih banyak terlibat dengan aktiviti jenayah berbanding golongan wanita (Jabatan Kebajikan Masyarakat 2015). Menurut Dodge, Coie dan Lynam (2006), golongan lelaki lebih cenderung terlibat dengan aktiviti jenayah kerana mereka mempunyai ciri-ciri individualisme seperti suka mengarah, mendominasi dan menakutkan orang lain.

Majoriti responden yang terlibat dalam kajian ini adalah berbangsa Melayu. Komposisi kumpulan etnik di Malaysia membuktikan bahawa golongan Melayu mencatatkan peratusan penduduk tertinggi iaitu sebanyak $68.6 \%$, diikuti Cina (23.4\%) dan India (7.0\%) (Jabatan Perangkaan Malaysia 2016). Oleh yang demikian, dapat dirumuskan bahawa keputusan kajian ini merupakan refleksi kepada populasi keseluruhan penduduk khususnya di Semenanjung Malaysia. Seterusnya, hasil kajian mendapati bahawa kebanyakan pesalah muda yang terlibat dalam kajian ini masih berstatus bujang. Secara amnya, individu yang belum berkahwin tidak terikat dengan sebarang tanggungjawab (Blokland dan Paul 2005). Situasi ini dijangka telah memberi kebebasan kepada responden untuk melakukan apa sahaja kerana kesan daripada perlakuan tersebut tidak akan memberi impak kepada pasangan atau anak-anak mereka.

Hasil analisis juga mendapati sebilangan besar daripada pesalah muda yang terlibat dalam kajian ini mempunyai kelayakan akademik setakat tingkatan 5 sahaja dan menganggur. Dapatan kajian ini bertepatan dengan pandangan pengkaji lepas seperti Mustard (2010) serta David, Loretta dan Gipsy (2015) yang menyatakan bahawa golongan muda yang menganggur lebih banyak terlibat dengan aktiviti jenayah kerana berhadapan dengan masalah kewangan serta mempunyai tahap pendidikan yang rendah. Jika dilihat dari aspek jenis kesalahan jenayah pula didapati sebahagian besar responden terlibat dengan kesalahan mencuri. Menurut Mouzos dan Carcach (2001), seseorang individu terlibat dengan kegiatan mencuri disebabkan faktor kesempitan kewangan serta terpengaruh dengan dorongan nafsu untuk mendapatkan barang-barang berharga tanpa perlu bekerja keras. Selain itu, menurut pandangan Blokland dan Palmen (2012), golongan muda lebih banyak terlibat dengan kesalahan mencuri kerana mereka mahu mendapatkan barang berharga dengan cara yang mudah serta perlakuan tersebut tidak memerlukan perancangan yang rapi. 


\section{Pengaruh Faktor Konsep Kendiri, Kesedaran Komuniti dan Sokongan Sosial Terhadap Pengintegrasian Sosial}

Analisis regresi berganda digunakan bagi mengenal pasti pengaruh faktor konsep kendiri, kesedaran komuniti dan sokongan sosial terhadap pengintegrasian sosial bagi pesalah muda di Malaysia. Jadual 8 menunjukkan keputusan analisis regresi berganda tersebut.

Jadual 8: Pengaruh faktor konsep kendiri, kesedaran komuniti dan sokongan sosial terhadap pengintegrasian sosial

\begin{tabular}{lccccccc}
\hline \multirow{2}{*}{ Model } & \multicolumn{2}{c}{ Pekali tidak piawai } & & Pekali piawai & & \multirow{2}{*}{ Sig. } \\
\cline { 2 - 3 } & $\beta$ & Std. error & & $\beta$ & & \\
\hline Pemalar & 0.478 & 0.130 & & - & & 3.688 & 0.000 \\
Konsep kendiri & 0.251 & 0.046 & & 0.273 & & 5.443 & 0.000 \\
Kesedaran komuniti & 0.181 & 0.041 & & 0.198 & & 4.396 & 0.000 \\
Sokongan sosial & 0.452 & 0.052 & & 0.440 & & 8.674 & 0.000 \\
\hline
\end{tabular}

Keputusan analisis regresi berganda menunjukkan konsep kendiri, kesedaran komuniti dan sokongan sosial mempunyai sumbangan yang signifikan terhadap pengintegrasian sosial. Sebanyak $64.6 \%$ varians telah diterangkan oleh ketigatiga peramal ini. Dapatan kajian menjelaskan bahawa faktor sokongan sosial $(\beta=0.440, p<0.01)$ merupakan peramal paling kuat kepada pengintegrasian sosial diikuti dengan faktor konsep kendiri $(\beta=0.273, p<0.01)$ dan faktor kesedaran komuniti $(\beta=0.198, p<0.01)$.

Hasil kajian ini adalah selari dengan penyelidikan yang telah dijalankan oleh Jason dan Chertok (1997), Graham dan Haidt (2010) serta Verrecchia et al. (2010) yang mendapati bahawa banduan yang menerima sokongan sosial yang berterusan daripada persekitaran sosial akan mempamerkan kesungguhan untuk mengintegrasikan diri dalam komuniti serta lebih bersedia untuk mengubah tingkah laku negatif yang terdapat dalam diri mereka. Selain itu, menurut Stephanie et al. (2016) dimensi sokongan sosial adalah amat penting bagi banduan lelaki agar mereka tidak mengalami gangguan emosi serta dapat mengintegrasikan diri dalam komuniti dengan yakin walaupun pernah terlibat dengan salah laku jenayah.

Secara amnya, sokongan sosial yang berterusan daripada persekitaran sosial menyebabkan seseorang banduan mempunyai kawalan kendiri yang tinggi serta lebih bersedia untuk mengintegrasikan diri dalam persekitaran sosial (Demaray et al. 2012). Menurut pandangan Demaray et al. (2012) serta Liu dan Chui (2014), banduan akan menunjukkan perubahan positif dari aspek emosi, motivasi dan 
persepsi sekiranya menerima sokongan sosial yang berterusan daripada individu yang signifikan dalam kehidupan mereka. Selain itu, Syme (2000) dan Teplin et al. (2006) menyatakan bahawa sokongan sosial yang berterusan daripada ahli keluarga adalah amat penting bagi individu yang pernah terlibat dengan salah laku jenayah memandangkan elemen ini mampu meningkatkan semangat dalam diri banduan serta membantu banduan untuk mengambil keputusan yang sewajarnya dalam kehidupan mereka.

Proses pengintegrasian sosial bagi pesalah muda adalah lebih mencabar berbanding pesalah dewasa kerana golongan ini tidak mempunyai pengalaman, pengetahuan serta kemahiran yang mencukupi untuk berhadapan dengan penerimaan negatif daripada anggota masyarakat (Salzer dan Baron 2006; Shinkfield dan Graffam 2009). Memandangkan kesemua responden yang terlibat dalam kajian ini masih muda, mempunyai tahap pendidikan yang rendah serta menganggur, maka adalah penting bagi mereka untuk menerima sokongan sosial yang konsisten daripada persekitaran sosial bagi mengurangkan risiko residivisme pada masa hadapan.

Keputusan kajian turut mendapati faktor konsep kendiri juga merupakan penyumbang signifikan kepada pengintegrasian sosial $(\beta=0.273, p<0.01)$. Menurut Verrecchia et al. (2010), pesalah muda yang mempunyai konsep kendiri yang positif berasa yakin untuk berinteraksi dan meluaskan jaringan sosial dengan ahli komuniti. Selain itu, Graham dan Haidt (2010) menjelaskan bahawa konsep kendiri yang positif dapat membantu seseorang banduan agar berfikiran secara terbuka semasa menerima kritikan dan persepsi negatif daripada persekitaran sosial, meningkatkan kemahiran daya tindak, mengelakkan sikap mementingkan diri sendiri serta meningkatkan sikap prihatin terhadap keperluan orang lain.

Marsh (1990) serta Jenkins dan Demray (2012) menjelaskan bahawa dimensi konsep kendiri yang positif akan membantu meningkatkan motivasi dalam diri banduan serta memberi keyakinan kepada mereka untuk menyuarakan pendapat apabila berkomunikasi dengan ahli komuniti sekaligus membantu banduan untuk berjaya dalam proses pengintegrasian sosial. Dalam konteks kajian ini, sokongan sosial yang diterima daripada persekitaran sosial diramal dapat membantu membina konsep kendiri yang positif dalam diri pesalah muda serta berjaya mengubah persepsi mereka terhadap ahli komuniti. Hal ini berikutan hasil kajian mendapati bahawa responden bersedia untuk berkongsi masalah yang dihadapi bersama ahli komuniti serta yakin berkomunikasi dengan anggota masyarakat. 
Hasil kajian menunjukkan bahawa faktor kesedaran komuniti menyumbang sebanyak $(\beta=0.198, p<0.01)$ terhadap pengintegrasian sosial. Menurut Jason dan Chertok (1997) serta Ward (2002), faktor kesedaran komuniti mampu meningkatkan motivasi pesalah muda untuk menjadi sebahagian daripada anggota masyarakat, mendorong pesalah muda memainkan peranan yang bermakna dalam komuniti serta mengurangkan risiko keterasingan sosial bagi individu yang pernah terlibat dengan kesalahan jenayah. Oleh yang demikian, dimensi kesedaran komuniti juga perlu diberi penekanan yang sewajarnya bagi membantu pesalah muda untuk berjaya dalam proses pengintegrasian sosial.

\section{IMPLIKASI KAJIAN}

Hasil kajian ini memberi implikasi kepada ahli profesional dalam bidang jenayah dan kebajikan sosial seperti pihak JKM dan Jabatan Penjara Malaysia dalam menyediakan program pencegahan dan pemulihan bagi golongan muda yang pernah terlibat dengan salah laku jenayah. Pihak yang berkepentingan boleh mengambil kira petunjuk-petunjuk yang menyumbang kepada pengintegrasian sosial yang telah dikenal pasti dalam kajian ini untuk membina sebuah modul pengintegrasian sosial yang komprehensif serta bersesuaian dengan budaya tempatan. Seterusnya, keputusan kajian ini juga memberi implikasi kepada agen kawalan sosial di Malaysia seperti Polis Diraja Malaysia yang mana maklumat berkaitan profil demografi pesalah muda yang berusia antara 18 hingga 21 tahun boleh digunakan sebagai garis panduan bagi membendung masalah jenayah dalam kalangan golongan muda.

\section{BATASAN KAJIAN}

Dalam proses menginterpretasi dapatan kajian yang telah diperoleh, beberapa limitasi kajian perlu dijelaskan. Kajian ini hanya berfokus kepada pesalah muda lelaki yang telah diperintahkan oleh pihak mahkamah untuk menjalani hukuman Perintah Khidmat Masyarakat bagi suatu tempoh tertentu. Justeru, skop kajian ini hanya tertumpu kepada (1) individu yang merupakan pesalah kali pertama; (2) tidak mempunyai rekod jenayah; (3) berusia 18 hingga 21 tahun; (4) tidak pernah ditempatkan di mana-mana pusat pemulihan akhlak atau penjara; (5) hanya pendekatan kuantitatif sahaja digunakan untuk mengumpul data kajian; serta (6) pemboleh ubah yang digunakan dalam kajian ini terbatas kepada empat faktor iaitu konsep kendiri, kesedaran komuniti, sokongan sosial dan pengintegrasian sosial sahaja. Oleh yang demikian, dapatan kajian ini tidak dapat digeneralisasikan kepada semua pesalah muda di Malaysia. 


\section{CADANGAN KAJIAN}

Berdasarkan kepada dapatan dan limitasi kajian yang telah dibincangkan, bahagian ini mengutarakan beberapa cadangan yang perlu dipertimbangkan bagi mengurangkan risiko residivisme serta membantu pesalah muda untuk berjaya dalam proses pengintegrasian sosial. Memandangkan masih tiada lagi satu model komprehensif berkaitan dengan pengintegrasian sosial yang bersesuaian dengan budaya tempatan, maka disarankan agar pihak JKM menggunakan Model Pengintegrasian Sosial yang telah dicadangkan dalam kajian ini (rujuk Rajah 1) sebagai garis panduan untuk menyediakan sebuah model pengintegrasian sosial bagi pesalah muda yang terlibat dengan salah laku jenayah. Model yang dicadangkan menerusi kajian ini dibina berdasarkan kepada keputusan analisis regresi berganda yang mendapati bahawa domain sokongan sosial, konsep kendiri dan kesedaran komuniti merupakan faktor penting yang dapat menyumbang ke arah pengintegrasian sosial. Oleh yang demikian, dalam proses membina sebuah model pengintegrasian sosial disarankan agar elemen sokongan sosial, konsep kendiri dan kesedaran komuniti diberi perhatian bagi membantu pesalah muda untuk mengintegrasikan diri dalam persekitaran sosial serta mengurangkan risiko keterasingan sosial.

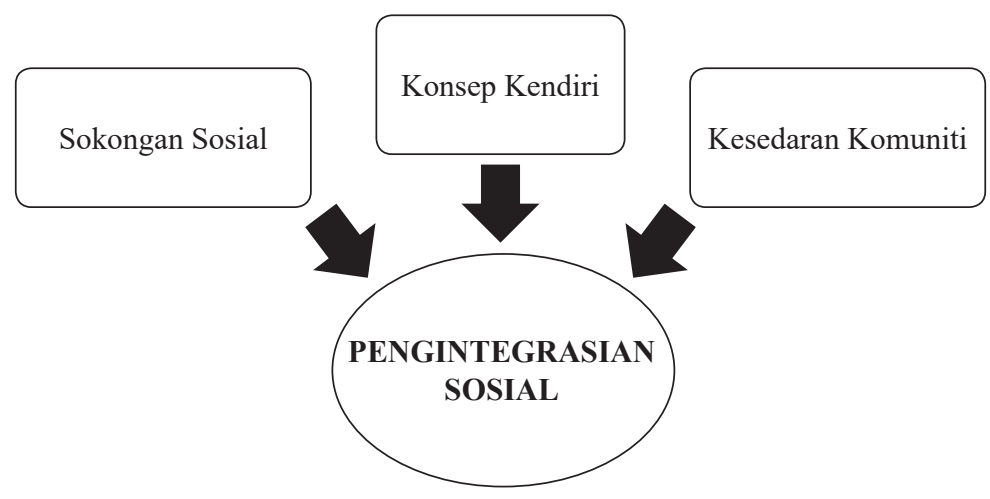

Rajah 1: Cadangan model pengintegrasian sosial.

Sebagai agensi yang bertanggungjawab dalam menguruskan dan melaksanakan hukuman Perintah Khidmat Masyarakat bagi pesalah muda di Malaysia, pihak JKM seharusnya merangka sebuah modul pengintegrasian sosial bagi membantu kumpulan sasaran. Justeru, beberapa perkara yang telah dikenal pasti dalam kajian ini perlu diambil perhatian agar modul pengintegrasian sosial yang bakal dibina kelak mampu menyumbang ke arah pengintegrasian sosial yang berjaya. Faktor sokongan sosial perlu diperkasa kerana hasil kajian menunjukkan sokongan 
sosial merupakan peramal utama kepada pengintegrasian sosial. Menerusi modul yang bakal dibina, disyorkan agar aspek pemantapan emosi dan penyelesaian masalah diberi perhatian yang sewajarnya. Sebilangan daripada pesalah muda yang terlibat dengan kajian ini menyatakan bahawa mereka masih lagi berasa sunyi dan keseorangan kerana tidak mempunyai sesiapa untuk berkongsi masalah serta jarang diajak oleh kenalan untuk melakukan sesuatu perkara bersama-sama dengan mereka. Selain itu, faktor konsep kendiri perlu diperkukuhkan lagi kerana keputusan kajian mendapati masih terdapat sebilangan daripada pesalah muda yang mengakui bahawa mereka tidak suka dengan diri sendiri, selalu berasa kecewa dengan diri sendiri serta kerap merasakan bahawa diri mereka tidak mampu melakukan sesuatu perkara dengan baik. Seterusnya, faktor kesedaran komuniti juga perlu dipertingkatkan kerana sebilangan daripada pesalah muda yang terlibat dalam kajian ini mengakui bahawa mereka masih tidak mengenali kebanyakan ahli komuniti yang tinggal di kawasan perumahan mereka serta berasa tidak selesa untuk berbincang dengan ahli komuniti sekiranya berhadapan dengan sesuatu masalah. Justeru, aktiviti kemasyarakatan yang melibatkan ahli komuniti perlu ditambah dalam modul yang bakal dibina kelak untuk membantu pesalah muda agar berjaya dalam proses pengintegrasian sosial.

Memandangkan sebilangan besar daripada pesalah muda mempunyai kelayakan akademik setakat SPM sahaja dan majoritinya sedang menganggur, maka dicadangkan agar latihan vokasional diberikan kepada golongan ini dengan kerjasama antara agensi agar pesalah muda dapat mencari pekerjaan yang bersesuaian dengan kelayakan mereka. Selain itu, disyorkan juga agar tenaga kerja pakar dilibatkan dalam memberi latihan kerja kepada pesalah muda sepertimana yang diperlukan oleh pasaran kerja semasa khususnya dalam bidang agrikultur, industri pemprosesan makanan dan penternakan haiwan bagi meningkatkan kadar guna tenaga dalam kalangan golongan muda. Di samping itu, disarankan agar pihak JKM bekerjasama dengan pihak industri bagi mengadakan pameran kerjaya untuk menawarkan peluang pekerjaan kepada bekas pesalah muda yang pernah menjalani hukuman Perintah Khidmat Masyarakat agar risiko residivisme dapat dikurangkan pada masa hadapan.

Kesemua responden yang terlibat dalam kajian ini terdiri daripada pesalah lelaki sahaja. Walaupun bilangan pesalah wanita yang sedang menjalani hukuman Perintah Khidmat Masyarakat adalah rendah berbanding pesalah lelaki, namun data yang dikumpul mungkin akan bersifat lebih menyeluruh sekiranya pesalah muda wanita turut dilibatkan dalam kajian sebegini pada masa hadapan memandangkan modus operandi serta cabaran dalam proses pengintegrasian sosial mungkin berbeza berdasarkan aspek gender. Selain itu, kajian ini hanya 
di jalankan di lapan buah institusi JKM di Semenanjung Malaysia sahaja. Oleh yang demikian, disarankan agar satu kajian silang budaya turut dijalankan di Sabah dan Sarawak untuk mengenal pasti corak jenayah dan trend pengintegrasian sosial bagi pesalah muda yang berada di kedudukan geografi yang berbeza.

\section{KESIMPULAN}

Hasil kajian menunjukkan faktor sokongan sosial, konsep kendiri dan kesedaran komuniti merupakan peramal signifikan bagi mencapai pengintegrasian sosial yang berjaya. Oleh yang demikian, diharap agar badan berkepentingan seperti JKM dapat memantapkan serta mengukuhkan lagi program pemulihan yang sedia ada bagi membantu pesalah muda untuk berjaya dalam proses pengintegrasian sosial serta mendorong golongan ini meneruskan kehidupan pro-sosial setelah selesai menjalani tempoh Perintah Khidmat Masyarakat.

\section{PENGHARGAAN}

Penulis merakamkan ucapan ribuan terima kasih kepada kakitangan JKM di atas sokongan dan kerjasama yang diberikan dalam menyempurnakan kajian ini. Ucapan penghargaan dan terima kasih juga ditujukan kepada pesalah muda di atas kesudian mereka menjadi responden dalam kajian ini.

\section{RUJUKAN}

American Educational Research Association; American Psychological Association; National Council on Measurement in Education. 1985. Standards for eductional and psychological testing. Washington, DC: American Psychological Association.

Baker, T.L. 1994. Doing social research. 2nd ed. New York: McGraw-Hill.

Beaver, K.M., M. DeLisi, D.P. Mears and R. Stewart. 2009. Low self-control and contact with the criminal justice system in a nationally representative sample of males. Justice Quarterly 26(4): 695-715.

Blokland, A.A.J. and N. Paul. 2005. The effects of life circumstances on longitudinal trajectories of offending. Criminology 43(4): 203-240. https://doi.org/10.1111/ j.1745-9125.2005.00037.x

Blokland, A.A.J. and H. Palmen. 2012. Criminal career patterns from adolescence to early adulthood. Aldershot UK: Ashgate.

Brislin, R.W., W.J. Lonner and R.M. Thorndike. 1973. Cross cultural research methods. New York: John Wiley \& Sons. 
Camp, D.L., U. Finlay and I. Lyons. 2002. Is sense of community an inevitable consequence of stigma? Social Science and Medicine 55(5): 823-834.

Carr, P.B. and C.M. Steele. 2009. Inflexible perseverance in sense of community and social support among offenders. Journal of Experimental Social Psychology 45(1): $853-859$.

Chavis, D.M., K.S. Lee and J.D. Acosta. 2008. The sense of community (SCI). https://www.senseofcommunity.com/soc-index/ (accessed 5 February 2021).

Chua, Y.P. 2009. Kaedah dan statistik penyelidikan buku 2: Asas statistik penyelidikan. 3rd ed. Selangor: McGraw-Hill Education.

. 2014. Asas statistik penyelidikan buku 3: Analisis data skala ordinal dan skala nominal. Selangor: McGraw-Hill Education.

Cohen, S. and H. Hoberman. 1983. Interpersonal support evaluation list (ISEL). Journal of Applied Social Psychology 13: 99-125. https://doi.org/10.1037/t06207-000

Cohen, L., L. Manion and K. Morrison. 2001. Research methods in education. 5th ed. London: Routledge/Falmer.

Creswell, J.W. and C.V.L. Plano. 2011. Designing and conducting mixed methods research. 2nd ed. Thousand Oaks, CA: Sage Publication.

Cullen, F.T. 2011. Beyond adolescence-limited criminology: Choosing our future. The American Society of Criminology 49(2): 287-330. https://doi.org/10.1111/ j.1745-9125.2011.00224.x

David, E.O., J.S. Loretta and E. Gipsy. 2015. Comparing male and female prison release across risk factors and post-prison recidivism. Women \& Criminal Justice 26(2): $11-18$.

De Vaus, D.A. 1993. Surveys in social research. 3rd ed. London: UCL Press.

Demaray, M.K., C.K. Malecki, S.S. Fredrick and K. Lyell. 2012. Promoting social support. Illnois, US: Northern Illinois University.

Demaray, M.K. and C.K. Malecki. 2014. Best practices in assessing and promoting social support. Illnois, US: Northern Illinois University.

Durkheim, E. 1897. Suicide: Suicide a study in sociology. Journal of Personality and Social Psychology 70: 1270-1280.

Dodge, K.A., J.D. Coie and D. Lynam. 2006. Aggression and antisocial behaviour in youth. Handbook of Child Psychology 6(1): 719-788. https://doi.org/10 .1002/9780470147658.chpsy0312

Felson, R.B. and D.A. Kreager. 2015. Group differences in sense of community: What is there to explain in social support? Journal of Race and Justice 5(1): 58-87.

Finks, A. and J. Kosekoff. 1985. How to conduct surveys: A step-by-step guide. Beverly Hills, CA: Sage.

Fleming, J.S. and B.E. Courtney. 1984. Multidimensional self-concept scale. Journal of Social Psychology 14: 9-12.

Frankfort, C. and I. Nachmias. 2000. Research methods in the social sciences series. Thousand Oaks, CA: Sage Publications.

Graham, J. and E.I. Haidt. 2010. Beyond beliefs: Religions bind individuals into moral communities. Personality and Social Psychology Review 14(1): 140-150. https://doi.org/10.1177/1088868309353415 
Greeno, C. and K. Kim. 2008. A confirmatory analysis of an abbreviated sense of community instrument: The MOS-SSS. Research on Social Work Practice 10(10): 1-7.

Grimm, L.R., A.B. Markman, W.T. Maddox and G.C. Baldwin. 2009. Stereotype threat reinterpreted as a regulatory mismatch among offenders. Journal of Personality and Social Psychology 96(2): 288-304.

Jabatan Kebajikan Masyarakat. 2015. Buku perangkaan tahunan JKM 2015. Putrajaya: Jabatan Kebajikan Masyarakat. http://www.jkm.gov.my/jkm/ uploads/files/penerbitan/Buku\%20JKM\%202015\%E2\%80\%A2Final.pdf (accessed 5 February 2021).

Jabatan Perangkaan Malaysia. 2016. Kelahiran mengikut daerah. https:/www. dosm.gov.my/v1/index.php?r=column/cthemeByCat\&cat=142\&bul_id $=$ c1pMajBBbVBRWDF6VGdBdStETU90dz09\&menu_id=bThzTHQxN1Zq MVF6a2I4RkZoNDFkQT09 (accessed 5 February 2021).

Jason, L.A. and F. Chertok. 1997. Measuring sense of community: Beyond local boundaries. The Journal of Primary Prevention 18(2): 193-212.

Jenkins, L.N. and M.K. Demaray. 2012. Social support and self-concept in relation to peer victimization and peer aggression. Journal of School Violence 11(1): 56-74. https://doi.org/10.1080/15388220.2011.630958

Lancaster, G., S. Dodd and P. Williamson. 2004. Design and analysis of pilot studies: Recommendations for good practice. Journal of Evaluation in Clinical Practice 10(2): 307-312.

Laub, J.H. and L. Sampson. 2001. Understanding sense of community and self-concept to desist from crime: An annual review of research. Chicago: University Chicago Press.

Lebel, T.P. 2012. Invisible stripes? Formerly incarcerated person's perceptions of stigma. Journal of Deviant Behaviour 33(2): 89-107. https://doi.org/10.1080/01639625 .2010 .538365

Liu, L. and W.H. Chui. 2014. Social support and Chinese male and female offenders prison adjustment. Prison Journal 94(1): 30-51.

Marsh, K.I. 1990. A multidimensional, hierarchical model of self-concept: Theoretical and empirical justification. Journal of Educational Psychology Review 2: 77-172. https://doi.org/10.1007/BF01322177

Maruna, S. 2001. Making good of offenders attitudes. Washington, DC: American Psychological Association.

Mashek, D., L.W. Cannaday and J.P. Tangney. 2007. Inclusion of community in self scale: A single-item pictorial measure of community connectedness. Journal of Community Psychology 35(2): 257-275.

Mohd Al Adib Samuri and Noor Aziah Mohd Awal. 2014. Berkeras patah berlembut lentur: Perintah bagi pesalah kanak-kanak. Selangor. Penerbit Universiti Kebangsaan Malaysia.

Mouzos, J. and C. Carcach. 2001. Weapon involvement in armed robbery. Australia: Australian Institute of Criminology.

Motzkin, J.C., C.L. Philippi, G.R. Kirk, J.P. Newman and O. Kiehl. 2012. Critical thinking in psychopathy, self-concept and integration. American Journal of Psychiatry 169(7): 743-749. 
Mustard, D. 2010. How do labour markets affect crime? New evidence on an old puzzle. IZA Discussion Paper 48-56, No. 4856. Bonn, Germany: Institute for the Study of Labor (IZA).

Othman Mohamed. 1999. Penulisan tesis dan analisis data dalam bidang sains sosial terapan. Selangor: Penerbit Universiti Putra Malaysia.

Pierson, H.I. 2010. Tackling social exclusion: Social support behaviour in marital interaction. Abingdon, Oxon: Routledge. https://doi.org/10.4324/ 9780203869253

Pilarska, A. and A. Suchanska. 2015. Self-complexity and self-concept differentiation: What have we been measuring for the past 30 years? Current Psychology 34(4): 723-743.

Piquero, A.R., W.G. Jennings, B. Diamond and J.M. Reingle. 2015. A systematic review of age, sex, ethnicity and race as predictors of violent. International Journal of Offender Therapy and Comparative Criminology 59(1): 5-26.

Rohany Nasir, Zainah Ahmad Zamani, Rozainee Khairudin and Wan Shahrazad Wan Sulaiman. 2011. Family functioning, self-esteem, self-concept and cognitive distortion among juvenile delinquents. The Social Sciences 6(2): 155-163.

Salzer, M.S. and A. Baron. 2006. Promoting community integration: Increasing the presence and participation of offenders in community life. Philadelphia: Temple University Collaborative on Community Inclusion.

Sekaran, U. and R. Bougie. 2011. Research methods for business: A skill building approach. 5th ed. New Delhi: John Wiley \& Sons.

Serin, R.I., D. Mailloux and N. Wilson. 2011. Practice manual for use with dynamic risk assessment for offender re-entry (DRAOR). Canada: Carleton University.

Shinkfield, A.J. and E. Graffam. 2009. Community reintegration of ex-prisoners: Type and degree of change in variables influencing successful reintegration. International Journal of Offender Therapy and Comparative Criminology 53: 29-34. https://doi.org/10.1177/0306624X07309757

Smallbone, S., W.L. Marshall and R. Wortley. 2013. A meta-analysis of sexual offenders. Journal of Counselling and Clinical Psychology 66(2): 345-357.

Stephanie, A., S. Sumihiro, M. Brittany, S. Faye, I. Taxman, T. Scott and S. Walters. 2016. Social support quality and availability affects risk behaviours in offenders. Health and Justice 4: 1-10.

Susan, M. and A. Murray. 1995. The social integration scale. Paper presented at the annual meeting of the American Educational Research Association (Chicago, IL, 24-28 March 1997) and the International Conference on Family Violence (Durham, NH, 4 July 1995).

Suszeka, H., K. Fronczyka, M. Koperab and N. Maliszewskic. 2018. Implicit and explicit self-concept clarity and psychological adjustment. Personality and Individual Differences 123: 253-256.

Syme, S.L. 2000. Social epidemiology: Crime and community. Oxford: Oxford University Press. 
Teplin L.A., K.M. Abram, G.M. McClelland, A.A. Mericle, M.K. Dulcan and J.J. Washburn. 2006. Psychiatric disorders of youth in detention. Juvenile Justice Bulletin April. https://www.ojp.gov/pdffiles1/ojjdp/210331.pdf (accessed 5 February 2021).

Tuckman, B.W. 1988. Conducting educational research. 3rd ed. New York: Harcourt Brace Jovanovick.

Turner, S. and J. Jannetta. 2010. Are sex offenders moving into social disorganization? Analysing the residential mobility of California parolees. Journal of Research in Crime and Delinquency 47: 558-590.

United Nations. 2012. Social integration: Social policy and development division. https://www.un.org/development/desa/dspd/social-integration-social-policy-and -development-division.html (accessed 5 February 2021).

Verrecchia, P.J., M.D. Fetzer, J.H. Lemmon and T.L. Austin. 2010. An examination of direct and indirect effects of ecological risks on persistent youth offending. Journal of Criminal Justice Review 35: 220-243.

Wallace, D.P. and C.J. Van Fleet. 2012. Knowledge into action: Research and evaluation in library and information science. Santa Barbara, CA: Libraries unlimited.

Ward, T. 2002. The management of risk and the design of good lives. Australian Psychologist 37: 172-179. https://doi.org/10.1080/00050060210001706846

Wasserman G.A., K. Keenan, R.E. Tremblay, J.D. Coie, T.I. Herrenkohl, R. Loeber and D. Petechuk. 2003. Child Delinquency Bulletin Series April. https://www.ojp .gov/pdffiles1/ojjdp/193409.pdf (accessed 5 February 2021).

Zainah Ahmad Zamani, Rohany Nasir, Rozainee Khairudin and Wan Shahrazad Wan Sulaiman. 2011. Family functioning as predictor towards self-concept among delinquent adolescents. Pertanika Journal of Social Sciences and Humanities 19(S): 83-89. 